\title{
Utilização da matriz importância-desempenho na análise estratégica: estudo em empresas de transportes urbanos
}

\author{
Use of importance-performance matrix in strategic analysis: study of urban transportation
}

Jamerson Viegas Queiroz ${ }^{[a]}$, Hélio Roberto Hékis ${ }^{[b]}$, Lelayne de Araújo Dutra ${ }^{[c]}$, Luíze Fernandes de Asevedo ${ }^{[d]}$, Maria

Luiza Azevedo de Medeiros ${ }^{[\mathrm{e}]}$

[a] Doutor em Engenharia de Produção pela Universidade Federal de Santa Catarina (UFSC), professor titular do Programa de Pós-Graduação de Engenharia de Produção da Universidade Federal do Rio Grande do Norte (UFRN), Natal, RN - Brasil, e-mail: jvqjamerson@yahoo.com.br

[b] Doutor em Engenharia de Produção pela Universidade Federal de Santa Catarina (UFSC), professor titular do Programa de Pós-Graduação de Engenharia de Produção da Universidade Federal do Rio Grande do Norte (UFRN), Natal, RN - Brasil, e-mail: hekis1963@gmail.com

[c] Graduanda em Engenharia de Produção pela Universidade Federal do Rio Grande do Norte (UFRN), Natal, RN - Brasil, e-mail: lelaynedutra@gmail.com

[d] Graduanda em Engenharia de Produção pela Universidade Federal do Rio Grande do Norte (UFRN), Natal, RN - Brasil, e-mail: luizeasevedo@gmail.com

[e] Graduanda em Engenharia de Produção pela Universidade Federal do Rio Grande do Norte (UFRN), Natal, RN - Brasil, e-mail: maluizamedeiros@gmail.com

\section{Resumo}

0 presente artigo tem como objetivo analisar estrategicamente como as empresas de transporte urbano da cidade de Natal, RN, apresentam-se, através da identificação dos principais critérios competitivos a serem adotados por esse setor, e como as organizações do estudo se comportam diante deles. Utilizou-se como ferramental teórico a matriz de importância-desempenho, interpretando seus valores a fim de avaliar o desempenho das empresas comparado à importância atribuída pelos clientes. A metodologia empregada baseou-se em uma pesquisa aplicada, a partir de um estudo multicaso exploratório de natureza qualitativa. A coleta de dados realizou-se por meio de entrevistas estruturadas, visitas in loco nas empresas de estudo e em órgãos relacionados, além da aplicação de questionários com clientes. A análise desses dados se deu de forma qualitativa e quantitativa. A partir deste diagnóstico e do uso da ferramenta matriz importância-desempenho de Slack et al. (1996), obteve-se como resultado a constatação das diferenças estratégicas entre as empresas estudadas, inferindo assim que o foco em qualidade, ao permear as operações de uma organização, pode colocá-la em posição de destaque no mercado.

Palavras-chave: Setor de transportes. Critérios competitivos. Matriz importância-desempenho.

\section{Abstract}

This article aims to analyze strategically how the urban transportation in the city of Natal, RN, is present, through the identification of key competitive criteria to be adopted by this sector, and study how organizations behave 
with them. Was used as a theoretical tool the importance-performance matrix, interpreting their values in order to assess business performance compared to the importance attached by customers. The methodology used was based on an applied research, from a multicase study exploratory qualitative. Data collection was conducted through structured interviews, site visits in the companies of study and related organs, as well as questionnaires to customers. The analysis of these data was qualitatively and quantitatively. Based on this diagnosis and the use of importance-performance matrix tool of Slack et al. (1996), was obtained as a result the strategic differences between the companies studied, thus inferring that the focus on quality, permeate the operations of an organization, can put it in a prominent position in the market.

Keywords: Transport sector. Competitive criteria. Importance-performance matrix.

\section{Introdução}

A ampliação da competição entre as empresas no mercado exige delas a busca por técnicas e métodos que as possibilitem um adequado posicionamento estratégico, de forma a garantir vantagens competitivas frente aos seus concorrentes. Afinal, como Michael Porter (1986) menciona, "qualquer empresa sem estratégia simplesmente corre o risco de se transformar numa folha seca que se move ao capricho dos ventos da concorrência".

A escolha do tema pode ser justificada tendo em vista que o setor de transporte coletivo por ônibus de Natal caracteriza-se como um importante serviço da cidade que não acompanhou o seu desenvolvimento urbano, resultando em um desempenho negativo frente aos usuários. Além disso, outra característica intrínseca ao setor na cidade é a presença de pequenas empresas familiares. Tal fato é digno de ser ressaltado, uma vez que, como afirmam Gimenez e Fagundes (2009), as principais correntes teóricas sobre estratégias competitivas enfatizam o desenvolvimento e a verificação de teorias em um contexto no qual as firmas, geralmente de grande porte, agem no sentido de maximizar o lucro, enquanto isso, em ambientes turbulentos e com fortes pressões governamentais, as pequenas empresas tendem a abdicar do lucro para focar sua estratégia na sobrevivência.

Gimenez e Fagundes (2009) ainda ressaltam que a preocupação com estudos em pequenas empresas, no nível estratégico, se justifica principalmente pelo fato de que há especificidades da gestão nas pequenas empresas, diferenciando-as das grandes, o que leva à necessidade de modelos conceituais apropriados a esse tipo de empresa.

A partir dessa realidade, os autores adotaram a estratégia de produção por se constituir como um direcionador de decisões adequado aos ambientes interno e externo às empresas.

0 presente artigo traz como objetivo analisar estrategicamente como as empresas de transporte coletivo por ônibus de Natal, RN, estão se comportando frente ao mercado. Associados ao objetivo geral traçaram-se os seguintes objetivos específicos: (i) verificar como cada empresa do estudo se comporta diante dos critérios competitivos adotados; (ii) traçar a matriz de importância-desempenho a fim de analisar o desempenho dessas empresas nos critérios estabelecidos, confrontando com a importância atribuída pelos clientes em cada um deles; e (iii) chegar a uma concepção de empresa ideal na cidade, a partir da comparação entre empresas de diferentes realidades.

Considerando tais proposições, a problemática de pesquisa gira em torno do seguinte questionamento: As empresas de transporte público de Natal apresentam um posicionamento estratégico frente ao mercado? Para responder ao problema proposto, objetivou-se entender a estrutura do setor, juntamente com suas oportunidades e limitações, a fim de avaliar os critérios competitivos mais importantes a serem adotados por companhias do setor.

A organização do presente estudo inicia-se com essa abordagem introdutória, seguida pela seção 2 , fundamentos teóricos, na qual se aborda a matriz importância-desempenho. A seção 3, metodologia, traz os meios de pesquisas utilizados durante o atual estudo. Posteriormente, a seção 4 expõe os estudos de caso realizados nas empresas A e B dentro das áreas estratégicas escolhidas. Em seguida, os resultados dessas análises podem ser observados na seção 5. Na seção 6, encontram-se as considerações finais do estudo, além de sugestões para possíveis trabalhos futuros e, finalmente, na seção Referências, são apresentadas as bibliografias utilizadas na pesquisa. 


\section{Fundamentos teóricos}

Uma estratégia empresarial pode se constituir em uma abordagem organizada para alcançar o sucesso do projeto. A definição da estratégia a ser adotada por uma empresa deve ser iniciada pela avaliação de seus conhecimentos e de suas habilidades e deficiências (MONTGOMERY; PORTER, 1998).

Dentro desse contexto, alguns autores, como Paiva, Carvalho Junior e Fensterseifer (2009) e Slack et al. (1996), citam os critérios competitivos como ferramentas que possibilitam às empresas um melhor aproveitamento de seus recursos, competências e oportunidades de mercado, em função das suas competências internas, do tipo de mercado em que deseja atuar, do grau de concorrência desse mercado e do tipo de produto que produz.

Para uma melhor compreensão, visualização e avaliação do nível de importância e de desempenho dos critérios competitivos, Slack et al. (1996) desenvolveu a matriz importância-desempenho, como principal ferramenta de controle de sua metodologia, a qual será dada enfoque na seção que segue, além de ser aplicada em um contexto real durante o desenvolvimento do trabalho.

\section{Matriz importância-desempenho}

A fim de elaborar a matriz importância-desempenho, considerou-se dentre os cinco critérios competitivos apontados por Paiva, Carvalho Junior e Fensterseifer (2009), os mais importantes a serem adotados por empresas desse setor, sendo eles: qualidade, desempenho de entrega, flexibilidade e "inovatividade".

Para que se possa entender a importância dos critérios competitivos no processo, devemos iniciar a avaliação da importância relativa de cada um dos objetivos de desempenho auxiliada por uma escala baseada na percepção dos clientes.

Fusco (2007) cita que uma forma especialmente útil de determinar a importância relativa dos fatores competitivos é distinguir entre os fatores "ganhadores de pedidos" e os "qualificadores".

A esse respeito, Slack et al. (1996) estabelece que os fatores competitivos ganhadores de pedidos são aqueles que diretamente ganham negócios adicionais para a operação, uma vez que são a principal razão pela qual os consumidores escolhem comprar o produto ou serviço. Se a operação melhora seu desempenho em fatores competitivos de pedidos, ela vai ou ganhar mais negócios ou aumentar as chances de ganhar mais negócios.

Critérios competitivos qualificadores são aqueles que podem não ganhar negócios extras se a operação melhora seu desempenho, mas pode certamente perder negócios se o desempenho cai abaixo de um ponto particular, conhecido como nível de qualificação. Se o desempenho de uma companhia estiver abaixo de um nível de qualificação, é improvável que ela ganhe pedidos. Todavia, uma vez acima do nível de qualificação, é improvável que um melhor desempenho nos critérios qualificadores por si só garanta que ganhe pedidos.

Fatores competitivos menos importantes, como o nome implica, são aqueles relativamente de pouca importância, comparados com outros. Os consumidores de fato raramente os consideram quando tomam decisões de aquisição. Nesse contexto, Slack et al. (1996) ainda estabelece uma escala para julgar a importância relativa dos fatores competitivos de uma empresa na realização de uma operação. Geralmente, a forma de fazer este tipo de análise é tomando as três categorias de fatores competitivos, acima mencionados, e dividir cada categoria em outras três categorias, representando posições fortes, médias e fracas.

Da mesma forma, Slack et al. (1996) estabelece uma escala semelhante que julga se o desempenho atingido por uma operação é melhor, igual ou pior do que aquele de seus concorrentes.

Fusco (2007) aponta ainda que dentre todos os aspectos que influenciam a atribuição de prioridades aos objetivos de desempenho, os mais imediatos são aqueles que surgem como resultado do estilo de vida e dos costumes dos clientes de uma organização.

Portanto, no intuito de se traduzir a necessidade dos clientes, dentre as várias ferramentas de apoio à análise estratégica de uma empresa, Paiva, Carvalho Junior e Fensterseifer (2009) destacam uma sequência de passos para a implementação da estratégia de produção. Tal sequência conduz à construção da matriz importância-desempenho de Slack et al. (1996), a qual mostra-se como uma prática maneira de se visualizar a comparação entre a importância que o cliente dá a um determinado critério, e o desempenho da empresa em análise frente a este mesmo critério. Assim sendo, a matriz demonstra a atuação da empresa em relação aos aspectos mais valorizados pelo cliente. 
A sequência de passos estabelecida por Slack et al. (1996) define as seguintes etapas no desenvolvimento da matriz:

a) identificação dos critérios competitivos e montagem do questionário a ser aplicado;

b) aplicação do questionário;

c) análise dos resultados e montagem da matriz importância-desempenho de Slack et al. (1996);

d) identificação das políticas atuais para cada categoria de decisão;

e) identificação das ações a serem tomadas (novas políticas) e sua priorização.

Através da análise destas etapas, surge a representação gráfica da matriz, que será explorada nas seções 4 e 5 do presente artigo, na qual o eixo das abscissas demonstra a importância dada pelo cliente frente a um determinado critério (Flexibilidade do serviço, por exemplo). 0 eixo das ordenadas, por sua vez, consiste no desempenho, em termos numéricos, da empresa frente ao mesmo determinado critério. A compilação das duas variáveis torna possível a análise a respeito das possíveis zonas de ações passíveis de serem tomadas pelo gestor, a fim de aprimorar o foco estratégico da empresa.

Paiva, Carvalho Junior e Fensterseifer (2009) estabelecem que a matriz possui quatro zonas: a apropriada, a de melhoramento, a de ação urgente e a de excesso. Se o critério cair na zona apropriada, ele estará contribuindo para a competitividade da empresa, pois tem um bom desempenho em relação aos concorrentes e é importante para os consumidores, ou ele tem um desempenho apenas razoável, mas não é valorizado pelo consumidor. Se cair na zona de melhoramento, o critério poderá ter uma importância grande, mas o desempenho da empresa é apenas razoável, ou pode ser pouco valorizado pelo cliente, e o desempenho é baixo. Se cair na zona de excesso, o desempenho é elevado, porém o critério é pouco valorizado pelo cliente. Por fim, se o critério cair na zona de ação urgente, o desempenho é pior que o da concorrência, e o critério tem uma importância elevada para o cliente.

A matriz mostra-se, então, como uma importante ferramenta no auxílio à visualização dos critérios a serem valorizados, bem como aqueles que não estão apresentando um bom desempenho nos critérios julgados pelo consumidor como de alta importância.
Dessa forma, a elaboração dessa matriz no presente estudo possibilitará o alcance dos objetivos propostos, além de responder à problemática de pesquisa.

\section{Metodologia}

Para a construção do presente artigo, foi empregada uma metodologia baseada na pesquisa aplicada, com um objetivo exploratório, a partir de um estudo de caso em duas empresas de transporte coletivo situadas na cidade de Natal. Os procedimentos técnicos de coleta de dados constituíram-se de pesquisas bibliográficas, visitas nas empresas e Órgãos Públicos, entrevistas estruturadas com gestores e funcionários desses órgãos relacionados, e aplicação de questionários com perguntas abertas e fechadas aos usuários do serviço em análise, respectivamente. A análise desses dados se deu de forma qualitativa e quantitativa descrita ainda nesta seção.

Considerando que os métodos de pesquisas utilizados possuem caráter de aprofundamento das ideias sobre o objeto de estudo, observa-se que, no contexto do setor de transporte urbano por ônibus, este se caracteriza como de modo exploratório. A base teórica utilizada baseou-se nos métodos do diagnóstico que apontam melhorias de qualidade operacionais (PIOVEZAN; CARPINETTI, 1999).

A fim de obter informações acerca do assunto a ser abordado, primeiramente foram realizadas pesquisas bibliográficas buscando embasar os autores e torná-los aptos a elaborar o questionário inicial aplicado nas organizações. Além disso, outro meio utilizado na pesquisa foi o estudo de caso exploratório, de natureza qualitativa, nas duas empresas, com o objetivo de fortalecer o referencial bibliográfico já estudado. 0 estudo de caso é uma investigação empírica que analisa um fenômeno contemporâneo dentro de seu contexto da vida real, especialmente quando os limites entre os fenômenos e o contexto não estão claramente definidos (YIN, 1994).

Durante o estudo foram realizadas visitas técnicas às empresas, denominadas no trabalho de Empresa A e Empresa B. Em um primeiro momento, as visitas foram realizadas na companhia A acompanhadas de entrevistas estruturadas, exploratórias e individuais com o diretor de operações.

Em seguida, realizou-se o estudo com uma forte companhia do setor, empresa B, visando o levantamento de informações para a confecção da matriz 
importância-desempenho e a possível comparação entre as organizações do estudo, a qual permitiu destacar as melhores práticas que empresas desse setor devem adotar.

Também foram utilizadas informações obtidas a partir de entrevistas com uma representante da Secretaria de Mobilidade Urbana da cidade. A análise das informações coletadas foi feita de forma qualitativa, buscando interpretar os dados coletados a partir da bibliografia levantada.

Para seu escopo este trabalho utiliza-se ainda da ferramenta estratégica matriz importância-desempenho, a qual expõe a importância e o desempenho dos critérios competitivos, de acordo com a percepção dos clientes e da empresa, assim como o posicionamento desses critérios na matriz de acordo com a avaliação dos clientes e da empresa.

Visando à confecção dessa matriz, aplicou-se o questionário a uma amostra da população usuária e às empresas em estudo, de modo a atender a sua estrutura. A primeira aplicação buscou mensurar a importância atribuída pelos usuários a cada um dos critérios competitivos adotados, já a segunda, com as mesmas questões, teve a finalidade de medir o real desempenho da empresa em relação aos concorrentes. As amostras obtidas com essa aplicação foram de caráter tanto quantitativo (ao questionar a importância em uma escala numérica) quanto qualitativo, por meio da interpretação dos resultados da matriz, como a posição estratégica em que as empresas se encontram e em que pontos elas podem melhorar.

\section{Estudo de caso}

Para a realização do estudo de caso foram analisadas duas empresas do setor de transportes urbanos, denominadas de A e B. As empresas selecionadas possuem ações antagônicas em relação à abordagem estratégica no setor do transporte coletivo na cidade de Natal.

\section{Empresa A}

Desde 1988, a empresa entrou no regime de concessão, ou permissão, pelo Decreto Lei n. 2.300/1986, atuando, desde então, principalmente na região sul de Natal. A empresa oferece hoje 13 linhas que focam três bairros da cidade, possuindo também três terminais, localizados nos conjuntos próximos aos respectivos bairros de atuação.

Para atender sua demanda, a empresa A possui uma frota de 80 ônibus, sendo 73 desses efetivos, dos quais cerca de $40 \%$ foram renovados recentemente, e os demais são usados como reserva. Segundo o diretor de operações da empresa, 80\% da frota é constituída por ônibus leves e $20 \%$ dela é composta por microônibus. De acordo com os dados fornecidos pela SEMOB-RN (Secretaria Municipal de Mobilidade Urbana), esta frota apresenta ciclo de vida com idade média de 5,86 anos do chassi dos ônibus, e de 5,83 para sua carroceria.

\section{Empresa B}

A empresa B está no mercado de Natal desde 1990. Sua missão se constitui em oferecer um transporte urbano eficaz, respeitando o meio ambiente, buscando o crescimento e a sustentabilidade da empresa.

Atualmente, de acordo com a gerente de Recursos Humanos, a empresa B possui em torno de 510 funcionários, dos quais 370 são motoristas e cobradores, que trabalham nas 13 linhas de ônibus da empresa, rodando diariamente e abrangendo todas as zonas da cidade, além de uma linha noturna que percorre as zonas Oeste e Sul. Seus terminais estão localizados em três bairros, sendo um deles o maior de Natal em frota de ônibus, com mais de 70 veículos, e onde também se encontra a unidade administrativa da empresa.

\section{Desempenho das Empresas A e B - critérios competitivos}

Para melhor analisar o desempenho das empresas foco do estudo de caso e sua adequação ao que se é exigido pelo setor na cidade de Natal, fez-se necessário identificar os critérios competitivos considerados de maior importância pelos usuários de ônibus da cidade e pelo órgão gestor (SEMOB). Assim, após aplicação de questionários, foram obtidos os critérios competitivos da qualidade, flexibilidade, desempenho de entrega e inovatividade.

A título de avaliação, será realizada uma análise qualitativa da performance das empresas foco do estudo, através da descrição acerca do desempenho de cada uma frente ao critério apontado, além de uma 
análise quantitativa, a qual será demonstrada nas matrizes importância-desempenho (Figuras 1 e 2). Para coleta de dados, foi realizada uma enquete com os clientes de transportes urbanos da cidade, acerca da valorização que cada cliente dá para cada critério demonstrado. Tal valorização é quantificada numa escala de 1 a 9, sendo o índice 1 atribuído a uma menor importância dada ao critério, enquanto o índice 9 é dado quando o cliente atribui a maior importância ao critério.
Para preenchimento do eixo das ordenadas, foram atribuídos, pelo grupo, índices, variando também na escala de 1 a 9. 0 índice 1 demonstra um menor desempenho por parte da empresa em análise, frente ao critério competitivo em foco. Já o índice 9 demonstra uma alta performance da empresa, em relação aos concorrentes, frente o critério competitivo em foco.

Dessa forma, como se mostra a seguir, foi realizado um diagnóstico das estratégias adotadas pelas

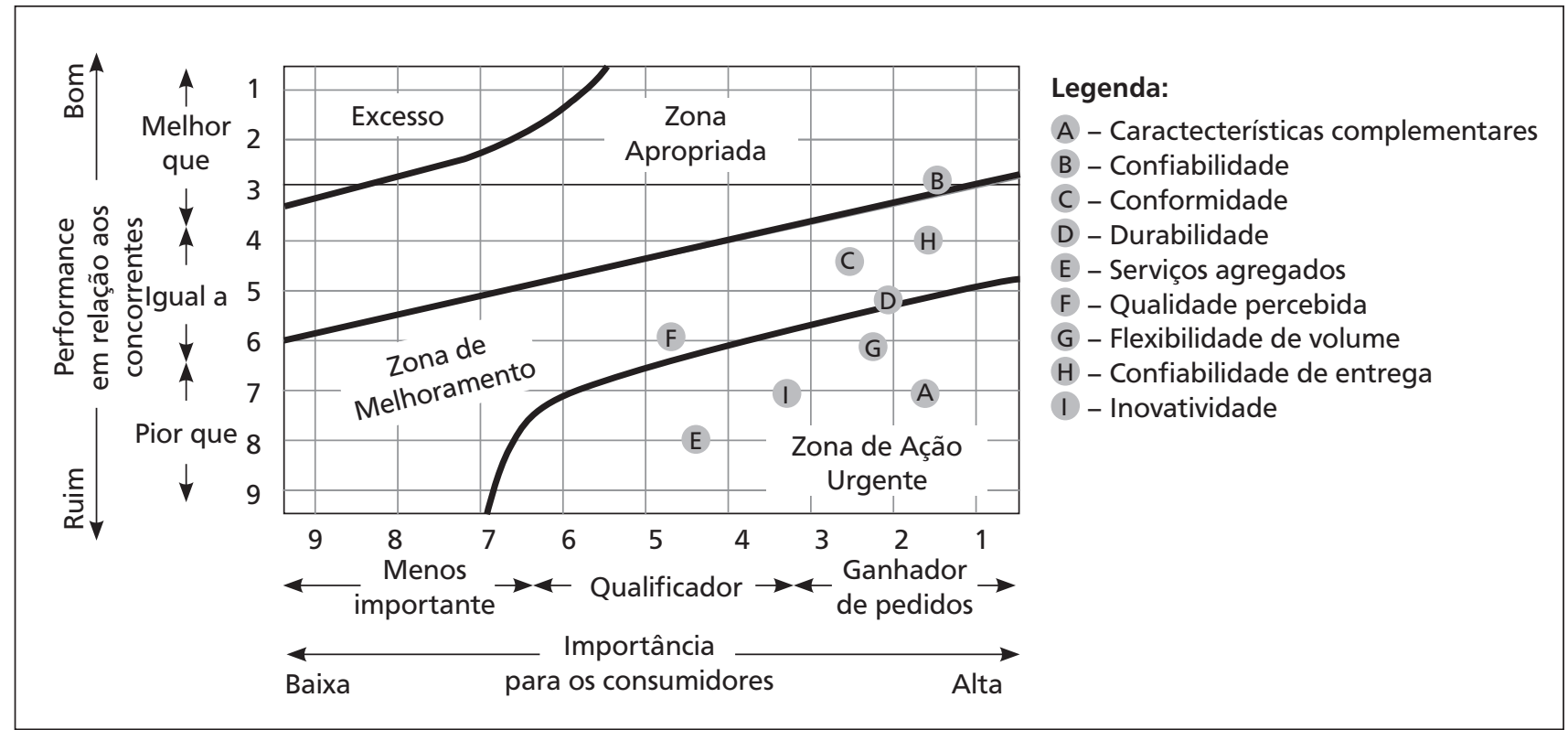

Figura 1 - Matriz importância-desempenho da empresa A

Fonte: Adaptado de SLACK et al., 2007.

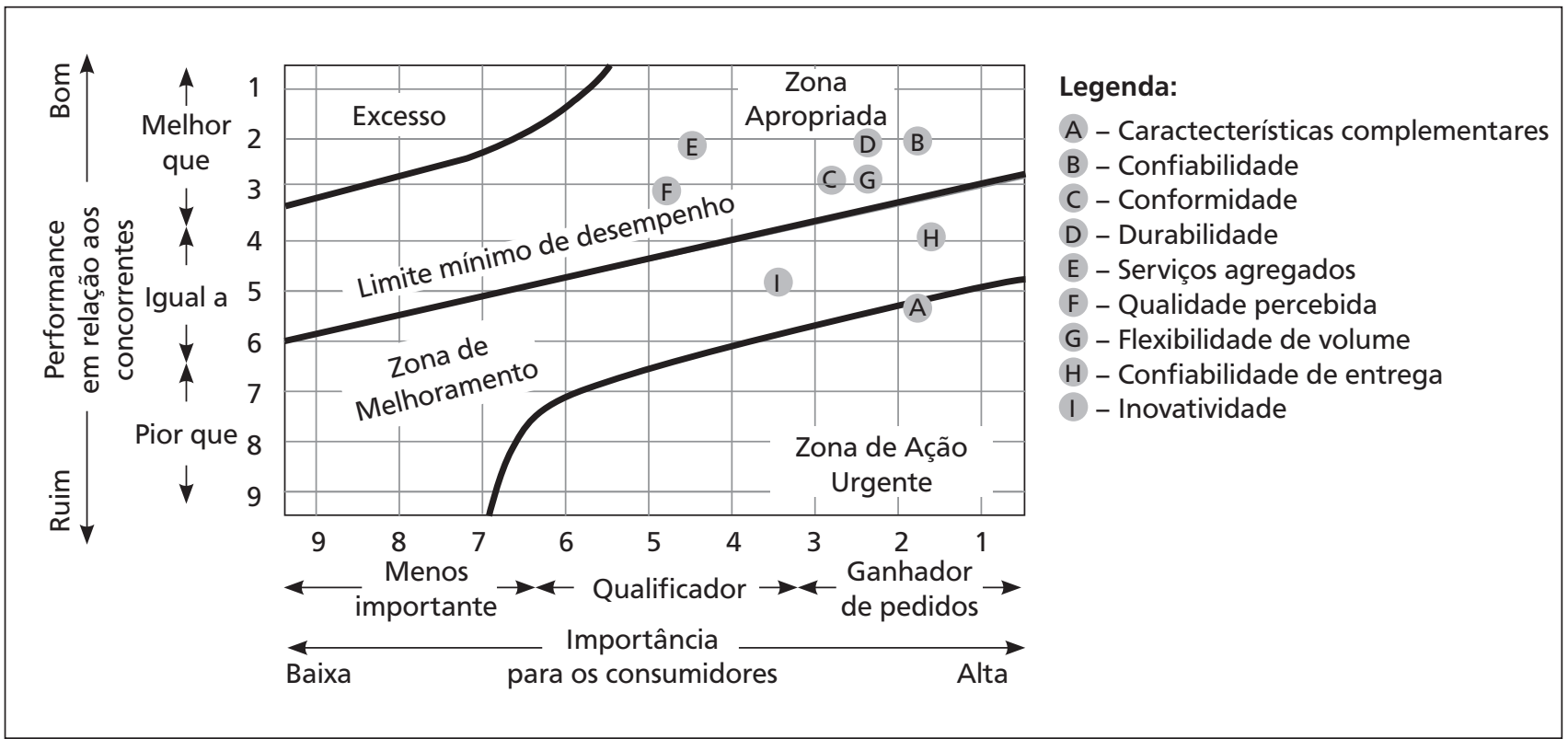

Figura 2 - Matriz importância-desempenho da empresa B

Fonte: Adaptado de SLACK et al., 2007. 
duas empresas, a partir da análise de seu desempenho nos critérios competitivos escolhidos e citados anteriormente. 0 diagnóstico mostra a realidade de cada empresa, apontando o desempenho extraído a partir das pesquisas realizadas, em relação a determinado critério, como é possível verificar nas referidas matrizes. Em seguida, na seção 5 - resultados -, faz-se um estudo comparativo entre as estratégias, levando em consideração seus posicionamentos na matriz importância-desempenho, na qual há o confronto dos dois eixos que a compõem, para auxílio na extração de resultados.

\section{Qualidade}

Dentre as oito dimensões da qualidade existentes, conforme Paiva, Carvalho Junior e Fensterseifer (2009), foram escolhidas seis, as quais caracterizam como de importância no setor. São elas: características complementares, confiabilidade, durabilidade, conformidade, serviços agregados e qualidade percebida.

\section{Características complementares}

No tocante às características complementares, estas podem ser observadas nas empresas de ônibus que investem no treinamento de seus funcionários, além de adequar seus ônibus às necessidades da sociedade, por exemplo, adaptando os veículos aos portadores de necessidades especiais.

Devido à importância desse critério, a SEMOB impõe às empresas a adoção de alguns projetos, principalmente relativos à acessibilidade dos ônibus. Além de participar desses programas, a empresa A investe em características complementares quando oferece treinamento aos seus funcionários de modo que esses se tornem aptos a melhor atender aos seus clientes, deixando-os mais satisfeitos. Esse treinamento ocorre em conjunto com diversas outras empresas do setor, a partir de iniciativas do SETURN (Sindicato das Empresas de Transporte Urbano de Passageiros do Município do Natal).

Já a empresa B busca trabalhar o pessoal qualificando motoristas e cobradores através da realização de treinamentos externos e internos, os quais vieram a se tornar modelo de destaque pelo sindicato local, o SETURN, sendo por isso instituído em outras empresas da cidade. A importância desses treinamentos se dá quando se considera as dificuldades de acompanhamento das ações executadas pelos motoristas e cobradores, na medida em que o setor de serviços é caracterizado pela simultaneidade entre o seu processo e sua percepção por parte do cliente.

Em virtude dessas observações, atribui-se à empresa A uma nota 5 de desempenho no critério observado, e à empresa $\mathrm{B}, \mathrm{o}$ valor 3 .

\section{Confiabilidade}

No que se trata da confiabilidade, esta pode ser alcançada principalmente através do baixo número de quebra dos ônibus, resultado de investimentos constantes e eficazes em manutenção dos equipamentos.

Para conseguir obter essa confiança dos clientes, a empresa A investe em manutenção preventiva, através da manutenção quando o ônibus atinge certa quilometragem, a fim de evitar falhas que prejudiquem seus usuários. No período de realização das manutenções, há uma substituição dos ônibus efetivos pelos reservas, porém, o que se vê na empresa A é um índice de quebras 30\% maior do que na outra empresa analisada, provavelmente graças à preferência, por parte da empresa A, por investimentos em manutenção corretiva, quando os automóveis chegam a um determinado estágio de vida, ao invés de se efetuar a compra de novas máquinas.

Da mesma maneira, na empresa B também são verificadas práticas de manutenção preventiva, sendo esta controlada também pela quilometragem percorrida pelas máquinas. Como já citado, é verificada uma maior cultura de renovação das máquinas por parte da empresa B, na medida em que o veículo atinge um determinado estágio de vida.

Dessa forma, atribuímos notas desempenho das empresas A e B, nesse critério, correspondentes a 7 e 8 , respectivamente.

\section{Durabilidade}

De acordo com a SEMOB, a dimensão técnica da durabilidade média dos ônibus da organização A é de, aproximadamente, 5,8 anos, o que se mostra acima da média dos concorrentes e dos objetivos traçados para ela. No ponto de vista da empresa, os novos ônibus, após dois anos de uso, equivalem ao mesmo custo de manutenção das máquinas antigas em funcionamento e, de acordo com o diretor de operações, 
estas novas máquinas exigem técnicos especiais e peças específicas que são de difícil obtenção no mercado, o que tem provocado um prolongamento no tempo de uso dos ônibus.

Por outro lado, na empresa B, vê-se uma maior prática de substituição das máquinas, sendo o tempo médio para troca de 4,7 anos. Consequentemente, como já citado, é verificado na empresa um menor número no índice de quebras dos ônibus, portanto, no quesito durabilidade, apesar de a empresa não deixar suas máquinas atingirem o tempo médio de quebra, atribuiu-se um melhor desempenho à empresa $\mathrm{B}$.

Dessa forma, foram designadas notas desempenho das empresas A e B, nesse critério, de 5 e 8 , respectivamente.

\section{Conformidade}

No que tange à conformidade do serviço oferecido pela empresa A, percebe-se que não há uma preocupação própria em oferecer serviços diferenciados e de qualidade, e, portanto, a organização não possui metas a serem cumpridas dentro desse contexto.

Já a empresa B consegue cumprir com o que se propõe adotando a estratégia de capacitar e satisfazer seus funcionários, alinhando-os à missão da empresa e transmitindo, consequentemente, uma maior qualidade ao serviço prestado.

Dessa forma, atribui-se ao desempenho das empresas A e B, respectivamente, as notas 5,5 e 7 .

\section{Serviços agregados}

No tocante a serviços agregados, o desempenho verificado na empresa A não condiz com o verificado no mercado, de modo que, nesse quesito, a empresa apenas investe o mínimo já estabelecido pelo órgão gestor, como a adoção de ônibus adaptados a deficientes.

Já a empresa B investe em projetos socioambientais em benefício da comunidade em que atua. É válido citar como exemplo o Projeto Adote o Verde, em parceria com a prefeitura de Natal, que torna a empresa responsável em preservar uma área verde da cidade. Na questão social, a empresa há cinco anos realiza a Semana do Idoso, na qual promove a interação de idosos de várias comunidades e instituições de Natal, proporcionando resultados significativos, como um maior profissionalismo dos operadores, culminando na redução do índice de reclamações.

A partir desses dados, foram atribuídas notas ao desempenho das empresas A e B, 2 e 8, respectivamente.

\section{Qualidade percebida}

A qualidade percebida em empresas de transporte é fruto da qualidade desempenhada por elas nos critérios considerados de importância no setor, ou seja, os critérios anteriormente apresentados, características complementares, confiabilidade, durabilidade, conformidade e serviços agregados. Isso se dá devido a suas colaborações para o desenvolvimento da marca e reputação das empresas.

Dessa forma, nota-se que a empresa A, por não possuir uma estratégia bem definida, não consegue obter uma força na sua marca frente ao mercado. Já a empresa B possui uma abordagem que visa satisfazer o cliente dentro e fora de seus ônibus, oferecendo, além dos serviços essenciais ao transporte, contribuições à sociedade. Devido a isso, atribui-se as notas 4 e 7 às empresas $A$ e $B$, respectivamente, representando seus desempenhos nessa dimensão da qualidade.

\section{Flexibilidade}

A flexibilidade é um critério percebido nas empresas de ônibus nas suas capacidades de adequação do volume de veículos e dos quadros de horários às variações do número de passageiros em determinados períodos sazonais. Tais quadros são estabelecidos pela SEMOB e aprovados pelas empresas. A fiscalização do cumprimento dos horários também é realizada pela SEMOB, e as empresas que não o cumprirem ficam sujeitas a multas.

Na empresa A, percebe-se uma baixa adaptação nesses quesitos, uma vez que as linhas oferecidas já foram há tempos definidas, não sendo constatadas modificações nos tempos recentes. Dessa forma, a empresa não desenvolveu a capacidade de mudar a variedade do serviço oferecido, de introduzir novos serviços ou transformar os existentes, de alterar o volume de ônibus em circulação e o quadro de horários das viagens. 
Na empresa B, por sua vez, verifica-se um melhor desempenho em relação à adequação do volume dos veículos frente às variações de sazonalidade, resultando num melhor atendimento à demanda verificada, seja em horários ou dias de picos, ou em períodos de menores demandas. Porém, na empresa também não foram verificadas maiores transformações no serviço já existente.

De acordo com essas informações, atribui-se o valor de 4 e 7 ao desempenho das empresas A e B, respectivamente, nesse critério.

\section{Desempenho de entrega}

A dimensão do critério do desempenho de entrega valorizada no setor trata-se da confiabilidade de entrega, que pode ser percebida no cumprimento dos quadros de horário. Porém, este critério pode ser influenciado por fatores externos à empresa, como as condições das vias públicas e engarrafamentos.

O tempo de viagem das linhas das empresas A e B variam entre 90 e 120 minutos, porém, quando não há uma fluência normal no trânsito, verificada principalmente em horários de pico, este tempo pode ultrapassar o estabelecido, provocando maior espera dos usuários pelo recebimento do serviço, podendo ocasionar em um desconforto de forma a comprometer a confiança deles à marca.

Apesar da forte influência pelos fatores externos, constatada no parágrafo anterior, vê-se, por parte das empresas em análise, um não cumprimento do quadro de horários estabelecido pelo órgão gestor. Nesse sentido, verifica-se um desempenho semelhante por parte das duas empresas, porém não satisfatório.

Às duas empresas em foco, foi designado um desempenho de entrega igual a 6 .

\section{Inovatividade}

No que tange ao critério da inovatividade, todas as companhias de ônibus da cidade aderiram ao Sistema de Automatizado de Bilhetagem Eletrônica, com o uso do equipamento GET - Gerenciador Eletrônico de Transporte. Outra inovação comum às empresas, impostas pela SEMOB, é a utilização de motores eletrônicos nos veículos, os quais emitem quantidades reduzidas de gases poluentes.
Dentre as empresas estudadas, a B é a única que investe além dessas inovações. A organização tem adotado a tecnologia, visando tornar seus processos mais eficientes, como com a implantação do sistema de GPS, o qual permite o monitoramento em tempo real dos trajetos realizados pelos motoristas, e instalação de câmeras filmadoras no interior de alguns de seus veículos, possibilitando mais segurança aos passageiros. Além disso, a empresa B fornece no seu sítio on-line ferramentas de interatividade simultânea, disponibilizando operadores para atendimento ao público.

Com base nessas informações, foram atribuídas notas ao desempenho das empresas estudadas de acordo com o determinado critério. A empresa A recebeu nota 3 e a empresa B, nota 5.

\section{Importância dada pelo cliente}

Através de pesquisas realizadas com usuários do transporte público por ônibus na cidade de Natal/ RN, pôde-se perceber que, dentre os critérios competitivos selecionados, os que representam de maior importância por parte do cliente são a qualidade e o desempenho de entrega. Dentro do critério da qualidade, foram destacadas as características complementares e a confiabilidade, principalmente no que se refere ao atendimento aos portadores de necessidades especiais e à confiança passada ao cliente no tocante ao funcionamento dos veículos. Com relação ao critério do desempenho de entrega, foi ressaltada pelos clientes a importância do atendimento aos horários das rotas.

\section{Resultados esperados}

A partir da análise da matriz, torna-se possível extrair resultados concretos acerca do confronto entre a importância dada pelo cliente a um determinado critério preestabelecido com o desempenho de cada empresa em relação ao critério em questão. Desta maneira, é viável a visualização dos critérios competitivos a serem priorizados pelas empresas, de modo a propiciar melhores informações no auxílio à tomada de decisões estratégicas por parte dessas.

Analisando o confronto verificado na matriz da Empresa A, a princípio, pode-se verificar, na zona 
apropriada, a presença do critério de confiabilidade, refletindo, portanto, que esse contribui para a competitividade da empresa. Os critérios de conformidade e qualidade percebida, por sua vez situados na zona de melhoramento, indicam uma necessidade, por parte da empresa, de aprimorar suas operações em ambos os aspectos, sendo a conformidade o que exige uma maior prioridade de atenção, pois se encontra projetado mais à direita na matriz. Na zona de ação urgente, observou-se que os critérios de serviços agregados, inovatividade e características complementares encontram-se na zona de ação urgente, por ordem de gravidade crescente, refletindo, assim, que o desempenho da empresa A encontra-se baixo, confrontando-se com uma alta importância dada pelos clientes aos critérios.

A análise dos resultados extraídos da matriz importância-desempenho da empresa B, por outro lado, reflete, de modo geral, um equilíbrio no desempenho dessa empresa em relação a cada critério, estando os seguintes critérios localizados na zona apropriada, em ordem crescente de desempenho: inovatividade, conformidade, qualidade percebida e confiabilidade. Desse modo, a empresa B atua de maneira conforme o esperado pelos clientes, tomando como base a importância dada aos critérios. Em relação aos serviços agregados, critério para o qual é demandada boa parte da atenção das operações da empresa, encontra-se na zona de excesso, refletindo um desempenho muito acima do valorizado pelo cliente. Na zona de ação urgente, encontra-se apenas o critério de características complementares, sendo assim, ambas as empresas devem demandar mais a atenção de suas operações a aspectos tais como o atendimento aos portadores de necessidades especiais, ou a própria qualidade no atendimento por parte dos funcionários.

Tomando os critérios encontrados nas zonas de melhoramento e de ação urgente, o Quadro 1 descreve as possíveis ações a serem tomadas, de maneira geral, pelos gestores das empresas A e B:

Quadro 1 - Resultados da matriz: possíveis ações a serem tomadas pelas empresas

\begin{tabular}{|c|c|c|}
\hline Critério & Zona & Medidas a serem tomadas \\
\hline $\begin{array}{l}\text { Características } \\
\text { Complementares }\end{array}$ & $\begin{array}{l}\text { Ação urgente } \\
\qquad(\mathrm{A} \text { e } \mathrm{B})\end{array}$ & $\begin{array}{c}\text { Ações voltadas à gestão da qualidade, tais como a adoção de sistemas ISO, práticas de } \\
\text { qualidade total, ou de Seis Sigma. }\end{array}$ \\
\hline Conformidade & Melhoramento (A) & $\begin{array}{c}\text { Buscar seguir uma única linha de ação nas diversas operações da empresa (do marke- } \\
\text { ting à produção). Só é possível quando os demais departamentos da empresa estão } \\
\text { alinhados à estratégia desta. }\end{array}$ \\
\hline Durabilidade & Ação urgente $(A)$ & $\begin{array}{l}\text { Práticas voltadas à qualidade do serviço, para isso utilizando-se de uma maior atenção } \\
\text { à manutenção/troca das máquinas utilizadas no processo produtivo. }\end{array}$ \\
\hline $\begin{array}{l}\text { Serviços } \\
\text { Agregados }\end{array}$ & Ação urgente $(A)$ & $\begin{array}{c}\text { A Internet mostra-se como uma ótima ferramenta para viabilizar investimentos rela- } \\
\text { cionados ao pré-atendimento, pós-atendimento e divulgação das ações da empresa. } \\
\text { De uma maneira geral, deve-se erguer esforços no intuito de aumentar o nível de } \\
\text { personalização do serviço. }\end{array}$ \\
\hline $\begin{array}{l}\text { Qualidade } \\
\text { Percebida }\end{array}$ & Melhoramento (A) & $\begin{array}{l}\text { Usar de ferramentas de marketing (publicidade aliada a uma excelência nas opera- } \\
\text { ções) para aumentar a percepção do cliente quanto à marca/reputação da empresa. }\end{array}$ \\
\hline $\begin{array}{l}\text { Flexibilidade de } \\
\text { Volume }\end{array}$ & Ação urgente (A) & $\begin{array}{l}\text { Focar as atenções das operações da empresa a uma melhor adequação à demanda, } \\
\text { considerando variações de sazonalidade. }\end{array}$ \\
\hline $\begin{array}{l}\text { Desempenho } \\
\text { de Entrega }\end{array}$ & $\begin{array}{l}\text { Melhoramento } \\
\qquad(A \text { e } B)\end{array}$ & Cumprimento ativo do quadro de horários estabelecido pelo órgão gestor. \\
\hline Inovatividade & $\begin{array}{l}\text { Ação urgente (A); } \\
\text { Melhoramento (B) }\end{array}$ & $\begin{array}{c}\text { Aquisição de novas tecnologias no processo produtivo do serviço e/ ou nas próprias } \\
\text { máquinas. }\end{array}$ \\
\hline
\end{tabular}

Fonte: Dados da pesquisa. 


\section{Conclusões}

Com a realização do estudo, nota-se que o setor de transporte na cidade de Natal não atende, hoje, a sua demanda de forma eficaz e eficiente, reflexo do descaso na qualidade do serviço oferecido aos usuários, por parte da maioria das empresas. Porém, as empresas as quais buscam adotar estratégia de produção, especificamente voltada aos critérios competitivos, mostram-se mais adequadas ao mercado. Tal adequação é refletida no melhor desempenho da empresa frente à concorrência, o que a torna referência no setor.

O trabalho desenvolvido conseguiu alcançar os objetivos propostos, na medida em que, como previsto, chegou-se à conclusão de que, dentre os critérios competitivos valorados pelo cliente de transporte coletivo, aqueles de maior relevância são os de qualidade, flexibilidade, desempenho de entrega e inovatividade. Torna-se possível, assim, a condução e desenvolvimento de uma estratégia recomendada para o setor, no intuito de se alcançar o conceito de uma empresa de transportes coletivos ideal.

Para a condução e auxílio à pesquisa, o método utilizado mostrou-se eficiente, visto que, com a mesma ferramenta desenvolvida, a matriz importância-desempenho, foi possível alcançar os diversos objetivos almejados nessa mesma proposta, de maneira que a matriz, ao mesmo tempo em que viabiliza a construção de uma estratégia ideal, considerando o quão importante um critério é para o cliente, também viabiliza uma análise acerca do real desempenho de uma empresa frente a este mesmo critério, auxiliando por si só o alcance de todos os objetivos propostos a princípio.

Percebeu-se nesse artigo a presença de duas vertentes: uma organização que não possui uma visão estratégica abrangente, não buscando posicionar e alinhar a empresa no mercado, ao limitar suas táticas apenas às operações internas à empresa, opondo-se dessa forma ao conceito de estratégia, como atua a empresa A. Por outro lado, tem-se uma organização que utiliza ferramentas estratégicas, considerando, assim, o ambiente externo e interno em que se encontra para sua tomada de decisões, caso da empresa B.

No tocante aos critérios competitivos adotados pelas organizações, com a adoção da ferramenta matriz importância-desempenho de Slack et al. (1996), foi possível confrontar o valor dado pelo cliente para um determinado critério da qualidade e o desempenho de cada empresa frente a esse critério, observando, assim, que a qualidade se apresenta como o mais relevante, garantindo um melhor alinhamento estratégico, graças à sua eficiência nesse tipo de serviço, aspectos comprovados com a análise do desempenho da organização B, a qual atende, de maneira mais conforme, aos critérios realmente valorizados pelo cliente, desempenho este verificado também na prática.

Além disso, o confronto entre a importância e o desempenho tornou possível a construção da empresa ideal, indicando onde e em que nível deve-se investir em um determinado critério, para a obtenção de vantagem competitiva. Observa-se, então, que a qualidade deve ser critério competitivo intrínseco ao setor de serviços, considerando que não faz sentido uma empresa voltada para o atendimento ao cliente possuir outra prioridade que não a qualidade desse atendimento, demonstrando a conformidade e/ou superação de suas expectativas.

Ao analisar o ambiente em que as empresas desse setor se encontram com o contexto de estratégia de produção, o estudo apontou como resultado algumas práticas oportunas visando garantir um melhor desempenho da companhia diante da sociedade. Dentre essas ações, encontra-se a implantação da estratégia de produção, a partir da adoção dos critérios competitivos que mais se destacam na população usuária, alinhados aos mais adequados para empresas desse setor.

Assim, algumas decisões a serem tomadas por companhias que almejam o ideal correspondem a investimentos no processo de recrutamento e seleção dos funcionários, além de treinamentos aos que já estão na empresa, possibilitando-os uma visão sistêmica. As organizações necessitam ter conhecimento de que, assim como o trânsito, os usuários precisam contar com profissionais equilibrados e adaptados às responsabilidades que o transporte de vidas humanas exige, do mesmo modo que eles devem passar por treinamentos constantes, visando seu aperfeiçoamento e ainda correção de alguma falha técnica ou na conduta operacional, buscando atingir, a partir de então, a excelência no atendimento ao cliente.

Outro ponto relaciona-se com a importância dada ao tempo médio da frota do ônibus e, consequentemente, as suas renovações e modernizações, para que esse esteja coerente com o padrão determinado pelo órgão gestor. É importante, também, investir em revisões corretivas e preventivas, a fim de garantir segurança e tranquilidade no trânsito. 
Com a atenção adequada aos critérios, as empresas possuirão mais chances de se destacar competitivamente no seu ambiente, desenvolvendo métodos e técnicas que definam o seu sucesso.

Dada a complexidade do setor em estudo, devido às limitações impostas pela legislação aliada a sua importância no desenvolvimento urbano da cidade, sugere-se para projetos futuros a realização de um estudo sobre as estratégias que devem ser adotadas pelas empresas para que elas possam apresentar melhor reação às variáveis de mercado, principalmente as grandes demandas oriundas da Copa 2014, que possui como uma de suas sedes a cidade de Natal.

\section{Referências}

FUSCO, J. P. A. Operações e gestão estratégica da produção. São Paulo: Arte \& Ciência, 2007.

GIMENEZ, F. A. P.; FAGUNDES, F. M. Ambiente, estratégia e desempenho em micro e pequenas empresas. Revista Brasileira de Estratégia, v. 2, n. 2, p. 133-146, 2009.

MONTGOMERY, C. A.; PORTER, M. E. Estratégia: a busca da vantagem competitiva. Rio de Janeiro: Elsevier, 1998.
PAIVA, E. L.; CARVALHO Jr., J. M. de; FENSTERSEIFER, J. E. Estratégia de produção e operações: conceitos, melhores práticas, visão de futuro. 2. ed. Porto Alegre: Bookman, 2009.

PIOVEZAN, L. H.; CARPINETTI, L. C. R. Estratégia empresarial e de manufatura: considerando sua importância na implantação de melhorias. Revista de Negócios, v. 4, n. 2, p. 55-63, 1999.

PORTER, M. E. Estratégia competitiva: técnicas para análise de indústrias e da concorrência. Rio de Janeiro: Campus, 1986.

SLACK, N. et al. Administração da produção. São Paulo: Atlas, 1996.

SLACK, N. et al. Operations management. New York: Prentice Hall, 2007.

YIN, R. K. Applications of case study research. Newbury Park: Sage, 1994.
Recebido: $17 / 10 / 2011$

Received: $10 / 17 / 2011$

Aprovado: 08/02/2012

Approved: 02/08/2012 